\title{
Microtubule Organization Is Essential for Maintaining Cellular Morphology and Function
}

\author{
Lijiang Huang $\mathbb{D},{ }^{1}$ Yan Peng $\mathbb{D}^{2},{ }^{2}$ Xuetao Tao $\mathbb{D}^{3},{ }^{3}$ Xiaoxiao Ding $\mathbb{D}^{4}$ Rui Li ${ }^{\mathbb{D}},{ }^{1,5}$ \\ Yongsheng Jiang $\mathbb{D}^{1},{ }^{1}$ and Wei Zuo $\mathbb{B D}^{1}$ \\ ${ }^{1}$ The Affiliated Xiangshan Hospital of Wenzhou Medical University, No. 291 Donggu Road, Xiangshan County, \\ Zhejiang 315000, China \\ ${ }^{2}$ Hangzhou Institute for Food and Drug Control, Hangzhou, Zhejiang, China \\ ${ }^{3}$ The Second Affiliated Hospital, Zhejiang University School of Medicine, Hangzhou, Zhejiang 310009, China \\ ${ }^{4}$ Department of Pharmacy, The People's Hospital of Beilun District, Ningbo, Zhejiang 315807, China \\ ${ }^{5}$ PCFM Lab, GD HPPC Lab, School of Chemistry, Sun Yat-sen University, Guangzhou 510275, China
}

Correspondence should be addressed to Rui Li; xiaoerrui1989@163.com, Yongsheng Jiang; shenren34127@163.com, and Wei Zuo; zuowei196412@163.com

Received 5 August 2021; Revised 10 January 2022; Accepted 26 February 2022; Published 7 March 2022

Academic Editor: Amadou Camara

Copyright () 2022 Lijiang Huang et al. This is an open access article distributed under the Creative Commons Attribution License, which permits unrestricted use, distribution, and reproduction in any medium, provided the original work is properly cited.

\begin{abstract}
Microtubules (MTs) are highly dynamic polymers essential for a wide range of cellular physiologies, such as acting as directional railways for intracellular transport and position, guiding chromosome segregation during cell division, and controlling cell polarity and morphogenesis. Evidence has established that maintaining microtubule (MT) stability in neurons is vital for fundamental cellular and developmental processes, such as neurodevelopment, degeneration, and regeneration. To fulfill these diverse functions, the nervous system employs an arsenal of microtubule-associated proteins (MAPs) to control MT organization and function. Subsequent studies have identified that the disruption of MT function in neurons is one of the most prevalent and important pathological features of traumatic nerve damage and neurodegenerative diseases and that this disruption manifests as a reduction in MT polymerization and concomitant deregulation of the MT cytoskeleton, as well as downregulation of microtubule-associated protein (MAP) expression. A variety of MT-targeting agents that reverse this pathological condition, which is regarded as a therapeutic opportunity to intervene the onset and development of these nervous system abnormalities, is currently under development. Here, we provide an overview of the MT-intrinsic organization process and how MAPs interact with the MT cytoskeleton to promote MT polymerization, stabilization, and bundling. We also highlight recent advances in MT-targeting therapeutic agents applied to various neurological disorders. Together, these findings increase our current understanding of the function and regulation of MT organization in nerve growth and regeneration.
\end{abstract}

\section{Introduction}

A multitude of cellular processes rely on the cytoskeleton, a filamentous scaffold of proteins that is essential for cell morphogenesis and division and intracellular transport. In eukaryotic cells, the cytoskeleton consists of three types of polymers: microtubules (MTs), actin filaments, and intermediate filaments. All three polymers provide a complex internal structure that maintains cellular homeostasis and fulfills different physiological functions. In general, actin filaments and MTs exhibit structural and regulatory interactions and such cytoskeletal crosstalk allows rapid intracellular reorganization, shape maintenance, and intracellular organelle movement $[1,2]$. Additionally, all three polymers undergo dynamic assembly and disassembly through whole cellular processes [3]. This dynamic instability generates forces that drive changes in cell shape and motility [4].

In many cells, MTs are created through the spontaneous assembly of alpha/beta-tubulin dimers into polarized filaments, which allows them to act as structural scaffolds and signaling platforms for cellular behavior. During nervous system development, MTs are abundant in axons and dendrites 
and have a nearly uniform polarity orientation [5]. This oriented array allows the directional transport of cargoes to be properly orchestrated. Given the distinct polarity, organization, and posttranslational modifications, it is not surprising that microtubule (MT) organization and orientation are one of the most essential and earliest developmental differences between axons and dendrites [6]. In axons, MTs are uniformly orientated with their plus-ends towards the axon tip, whereas in dendrites, MTs are either oriented in the same manner or the opposite manner, depending on neuronal type and organism $[7,8]$. Proper MT function as well as proper functioning of their assortment of interacting and regulatory proteins and regulatory pathways is particularly important in neurons. Abnormalities of the MT system in axons and dendrites, i.e., MT depolymerization, loss, or dysfunction or disorganized MT arrays, are a common insult during the pathogenesis of nerve traumatic disorders $[9,10]$.

Here, we summarize our current understanding of the basic biological features of MT organization within the cell, focusing on MT self-assembly and the direct participation of microtubule-associated proteins (MAPs) in MT nucleation, stabilization, and postmodification. We also discuss the current state of microtubule-stabilizing agents (MSAs), a new pharmacological intervention for treating central nervous system disorders, and address several microtubuledestabilizing agents (MDAs) as therapeutic strategies for suppressing cancer activity and vasculogenesis. Such diversified MT functions may provide us with new insights into MT-targeting therapies that mitigate structural and functional alterations linked to nervous system disorders.

\section{MT Organization and Dynamic Regulation in Eukaryotic Cells}

MTs are hollow cylindrical tubes consisting of repeating $\alpha$ tubulin and $\beta$-tubulin heterodimers that play central roles in cellular morphogenesis, division, and development. The $\alpha$-tubulin subunit is the minus-end in MT networks and exhibits slow growth rates and fast dissociation rates. The $\beta$-tubulin subunit is the plus-end and exhibits opposite growth and dissociation rates relative to the $\alpha$-tubulin subunit. Within eukaryotic cells, tubulin dimers can form heterogeneous and dynamic protofilaments by aligning head to tail; approximately 13 protofilaments of MT are needed to form a hollow tube. During the process of MT polymerization, it usually exhibits dynamic instability, i.e., assembly and disassembly occur simultaneously, which is essential for normal functioning of the MT cytoskeleton [11]. The mechanism of such behavior is governed by the presence of two distinct states of GTP-GDP shafts at the $\beta$-tubulin end [12]. When tubulin dimers are free in solution, MT at the $\beta$-tubulin end is under the GTP-bound state and can be exchanged [13]. After incorporation of the tubulin dimers into the MT, $\beta$-tubulin hydrolyzes the GTP to GDP [14]. Thus, as long as subunits of GTP-bound $\beta$-tubulin form a GTP-tubulin cap at the plus-end [15], MTs can grow, but when GTP at the exchangeable site (E-site, located at the $\alpha / \beta$-tubulin dimer of the plus-end) becomes hydrolyzed to GDP due to the GTPase activity of $\beta$-tubulin, the MT enters a state of shortening. With the help of the GTP-tubulin cap and E-site, MT polymerization and depolymerization occur primarily at the plus-ends.

During the initial stage of MT formation (also termed MT nucleation, Figure 1), $\alpha / \beta$-tubulin dimers need a template to guide assembly and elongation. This template is named the gamma-tubulin ring complex $(\gamma$-TuRC), which consists of numerous $\gamma$-tubulin molecules with various types of gamma-tubulin complex proteins (GCPs) [3]. GCPs at the $\mathrm{N}$-terminal regions can interact directly with mitotic spindle organizing protein 1 (MZT1), a key regulator of the centromere structure [16]. The MZT1 protein is capable of binding to the N-terminal centrosomin motif 1 (CM1) domain of CDK5RAP2, a tethering protein that can recruit and bind $\gamma$ TuRC to diverse microtubule organizing centers (MTOCs), including the centrosome, Golgi apparatus, or mitotic chromatin $[17,18]$. After forming the $\gamma$-TuRC ring structure, $\gamma$ tubulin molecules can anchor the minus-end of $\alpha / \beta$-tubulin dimers to support a lateral association between $\alpha / \beta$-tubulin dimers and polymerize into MTs with parallel orientations [19]. Thus, MT nucleation plays a crucial role in regulating MT self-assembly in various eukaryotic cells.

\section{Types of MT Regulatory Proteins}

MT stability, predominantly its mass and conformation, is controlled by the activities of several MAPs. They participate in a plethora of cellular processes, including cellular division, polarization, and intracellular transport, and can be categorized into MT-stabilizing proteins and MT-destabilizing proteins. The former group including MAP2, Tau, and Doublecortin (DCX), can interact with different MTbinding domains to bundle neighboring MTs [20]. MTdestabilizing proteins, on the other hand, perturb specific interaction nodes within the MT minus-end by accelerating the frequency of MT depolymerization. Different MAPs may regulate the stability and dynamics of MTs by creating different assembly patterns, either by altering the stability of lateral bonding tip extensions or altering the delivery of tubulin subunits to the tip $[21,22]$. This regulation creates spatial and temporal patterns in the MT network within cells that are particularly important for cell morphogenesis, division, and physiology [23]. Although some MAPs remain poorly understood due to their high degree of homology, a huge number of mammalian MAPs have been characterized using proteomics and the construction of transgenic animal models $[24,25]$. Here, we highlight some typical MAPs involved in their features and physiological functions as well as in the molecular mechanisms of stabilizing MTs.

MAP2, a microtubule-associated protein (MAP) family member, produces four different isoforms (MAP2A-D) according to alternative splicing of the same transcript. Generally, these four isoforms are highly expressed in differentiated neuronal dendrites, resulting in their utilization for labeling mature neurons. In addition, MAP2C and MAP2D are also widely distributed in glial cells. During the stages of neuronal development, MAP2 modulates MT-mediated cellular transport to participate in nucleation and stabilize MTs and bundling [26]. In particular, MAP2 is expressed in 

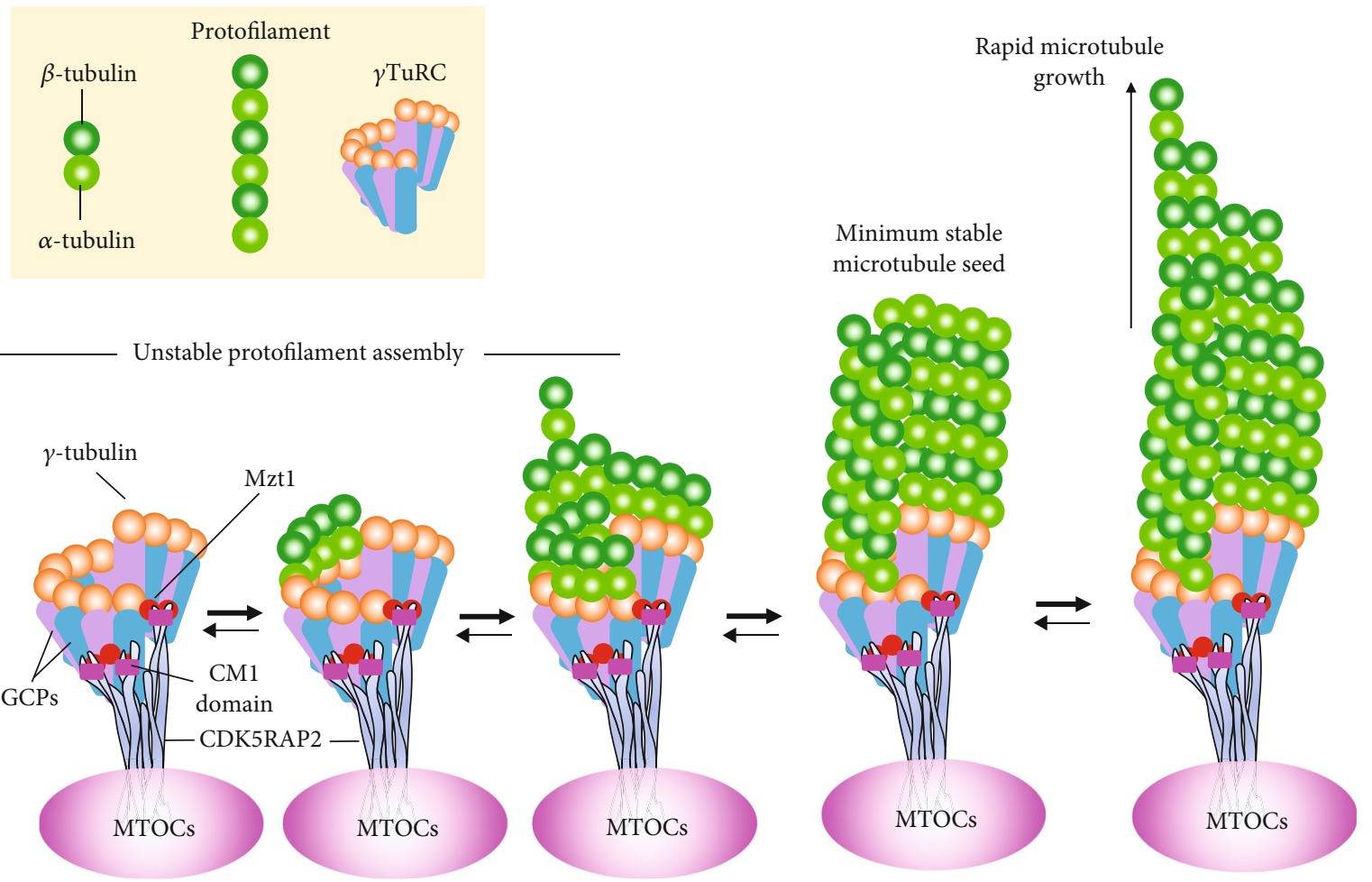

FIgURE 1: The process of $\gamma$-TuRC-mediated MT nucleation. The formation of the $\gamma$-TuRC ring structure and its interaction with $\alpha / \beta$-tubulin dimers are described above. Briefly, the $\gamma$-TuRC complex can be recruited to various MTOCs via linking other accessory proteins to form a ring-like structure. Such structure allows the rapid growth of complex MT networks via $\gamma$-tubulin molecules interacting longitudinally with the MT minus-ends. It should be noted that MTs have the characteristic of dynamic instability, which allows MTs to spontaneously switch between assembly and disassembly phases. If there are sufficient tubulin dimers, MT polymerization can progress rapidly.

mature dendrites and is critically essential for protein synthesis and organelle biogenesis, as it controls cargo sorting at the predendritic filtering zone $[27,28]$.

Another MAP, Tau, also supports the stability and dynamics of the cytoskeleton but is mainly enriched in axons $[29,30]$. While MTs and Tau share a conserved carboxy-terminal domain that can specifically interact under physiological conditions, the amino-terminal non-MTbinding domain, another region of the Tau protein, provides a large area for interacting with other cellular components, such as actin, kinesin, and dynein, thus ensuring the movement of cargo packages from the cytoplasm to the distal end of the axon [31,32]. Over the last several years, a larger number of studies have revealed that the Tau protein is encoded by the MAPT gene and can interact with MTs in a "kiss-and-hop" fashion, namely, temporarily dwelling on a single MT before hopping to the adjacent MT, regulating MT dynamics $[33,34]$. This dynamic MT Tau interaction is maintained mainly through electrostatic interactions between the positively charged MT-binding region and the negatively charged acidic glutamate-rich C-terminal regions of the tubulin surface $[35,36]$. In addition to these electrostatic interactions, posttranslational modifications of Tau, mainly phosphorylation and acetylation, strongly affect MT-Tau binding and thereby have the potential to modulate the organization of MTs $[37,38]$.

DCX is a unique MAP that has been shown to be involved in MT assembly, turnover, and posttranslational modification of $\alpha$ - and $\beta$-tubulin proteins [39]. Binding of DCX to tubulin increases MT homeostasis in neurons, which can be disturbed via knockout of the DCX gene sequence using an inducible transgenic mouse approach [40]. Additionally, DCX is expressed in various regions of the developing nervous system and is regarded as a gold standard biomarker for identifying neuronal precursors and migration during adult neurogenesis [41, 42].

In addition, fibroblast growth factor 13 (FGF13) acts as an intracellular MAP that promotes axonal development, neuronal polarization and migration, and brain development [43]. It is rich in the central nervous system, especially for the developing brain. The regulatory mechanism by which FGF13 induces MT polymerization and stabilization is through binding to a tubulin-binding domain to directly interact with tubulin and colocalize with MTs in the growth cone [44]. Accumulating evidence suggests that overexpression of FGF13 enhances axonal regeneration and functional recovery by maintaining MT stabilization following spinal cord injury (SCI) and FGF13 deficiency causes cognitive impairment due to delayed neuron migration in both the cortex and hippocampus [44, 45]. Overall, these MTstabilizing proteins are essential for cytoskeletal reorganization, growth orientation, and intracellular organization.

Several regulatory proteins can interact with dynamic MT minus-ends to catalyze the removal of tubulin subunits. These MT-destabilizing proteins are mainly MT depolymerases or the members of the calmodulin-regulated 
spectrin-associated protein (CAMSAP) family. MT depolymerases, also known as kinesin family proteins, have been reported to break the lateral links of protofilaments and tear off the tubulin monomer from the spindle by attaching to the minus-end of MT [46]. Currently, over 40 known kinesins have been identified in mammalian cells and are constitutively expressed in neurons [47]. Kinesins are known to modulate various cellular functions, including energy transport, spindle elongation during cell division, and alteration of the MT dynamics [48]. Some studies have indicated that kinesins that regulate neuronal behavior and function are closely associated with the MAPK cascade. For instance, kinesin- 8 connects and interacts with the MAPK pathway to induce neuronal migration and differentiation [49]. Meanwhile, kinesin-5-induced MAPK signaling activation regulates myelination of the nervous system and promotes neuronal polarization and morphogenesis in cortical pyramidal neurons $[50,51]$. Similar to the functions of the kinesin family, the CAMSAP family also binds to free minus-ends of MTs to slow tubulin addition, leading to the arrest of their growth at minus-ends [52]. This family of proteins, including CAMSAP1-3, contains an amino-terminal $\mathrm{CH}$ domain. In worms and mammals, CAMSAPs are localized to the outermost tips of the minus-ends, which play a crucial role in transporting new MTs into an axon or a dendrite in neuron differentiated from neural stem cells (NSCs) $[53,54]$. A study by Cao et al. recently proposed that CAMSAP2 was capable of slowing minus-end polymerization and facilitating polarized cargo trafficking, which strengthened MT organization [55]. Additionally, Pongrakhananon et al. revealed that CAMSAP3 was required to retain a dynamic pool of MTs as it prevented $\alpha$ TAT1-mediated acetylation and thus maintained neuronal polarity [56]. Depletion of neuronal CAMSAP3 reduced dynamic MTs, resulting in supernumerary axon formation [56].

\section{MT Organization in Neurons}

A vertebrate neuron is an exquisitely polarized cell whose structure is composed of a cell body, a single elongated axon, and several dendrites [57]. In neuronal networks, axons play the major role in transmitting information and transporting macromolecules, while dendrites form numerous spine apparatuses for receiving information $[58,59]$. During neuronal development, the cell body initially produces several short motile lamellipodia (stages 1-2); one of these lamellipodia rapidly becomes the axon (stage 3 ), while the remaining neurites transform into dendrites and gradually mature to build neural networks (stages 4-5) [60]. At stages 1-2, a fan-shaped structure is found at the tip of the growing axon; this growth cone can perceive the surrounding environment changes and regulates the rate and direction of axon extension, guiding axons over long distances to connect their specific targets [61]. If axons fail to grow due to a hostile local environment (e.g., hemorrhages, ischemia, the accumulation of inflammatory factors, myelin debris, or axonal inhibitory molecules), the tips of growing neurites form retraction bulbs. According to the cytoskeletal organization, the growth cone can be separated into three regions: peripheral $\left(\mathrm{P}_{-}\right)$and central (C-) regions as well as the transitional zone (T-zone). The P-region contains actin-rich lamellar protrusions, and its surface stretches out many lamellipodia and filopodia, which are pivotal to control the extension and retraction of the growth cone [62]. The C-region, located at the base of the growth cone, is the MT-rich region contiguous with the axonal shaft that shapes the morphology of the growth cone and orchestrates cytoskeletal remodeling. The T-zone is located between the P- and C-regions. Such domain encompasses actin arcs, a dense meshwork of actin filaments that creates a barrier to hinder MT forward from the Cregion to the P-region $[63,64]$. For the growth cone to advance, a dense MT array from the C-region must penetrate the T-zone to reach the P-region, preferentially polymerizing after incorporation of GTP to the $\beta$-tubulin subunit [65]. Axonal protrusion, retraction, and turning in response to signaling cascades require the coordination of the neuronal MT network and the actin cytoskeleton within the growth cone [66]. Specifically, recent studies have shown that growth cone steering and advancement in response to environmental cues depend on MT assembly and dynamics $[67,68]$. Thus, understanding the intrinsic regulatory mechanisms of MT dynamics and function within the growth cone may provide therapeutic targets for interventions that improve axon growth and guidance during neurodevelopment and neuroregeneration following injury.

Neuronal MTs are arranged in a specific orientation [9, 69]. In axons, MTs have an almost exclusive plus-end-out orientation, whereas in dendrites, MTs have an antiparallel organization with equal proportions of plus-end and minus-end towards the soma [70]. This distinct orientation is partially regulated by kinesin and dynein, two molecular motor proteins that cooperate with protofilaments to drive MT elongation from the C-region to the P-region [71, 72]. Moreover, these proteins also act as vectors for transporting organelles and other cargo towards axons or dendrites [73]. Kinesins have been determined to move cargo to axon terminals, whereas MTs of mixed polarity allow dynein motors to drive cargoes, such as that from the Golgi apparatus and ribosomes, specifically into dendrites [74]. Such distinct MT polarity patterns and cargo sorting are essential for distinguishing neurons into axons or dendrites (Figure 2).

The overall appearance and arrangement of the MT network within neurons are variable and depend on their maturation stage $[75,76]$. At the early stages of initial neurite outgrowth, MTs are of mixed polarity as short mobile polymers are rapidly released to be used by other MTs for their elongation. However, at the later stages of development, i.e., adult neurons, MTs have minus-end-out orientation with hundreds of micrometers in length and act as major long-distance railways for organelle transport. During development, MT orientation according to a network of feedback loops is essential for maintaining proper neuronal shape and inducing neuronal polarization $[77,78]$. Upon neuronal polarization, posttranslational modifications of MTs in the nascent axon provide selective transport routes that increase the neurite length-dependent feedback and anterograde transport $[79,80]$. The establishment of a normal feedback loop network is required for the activation of various 


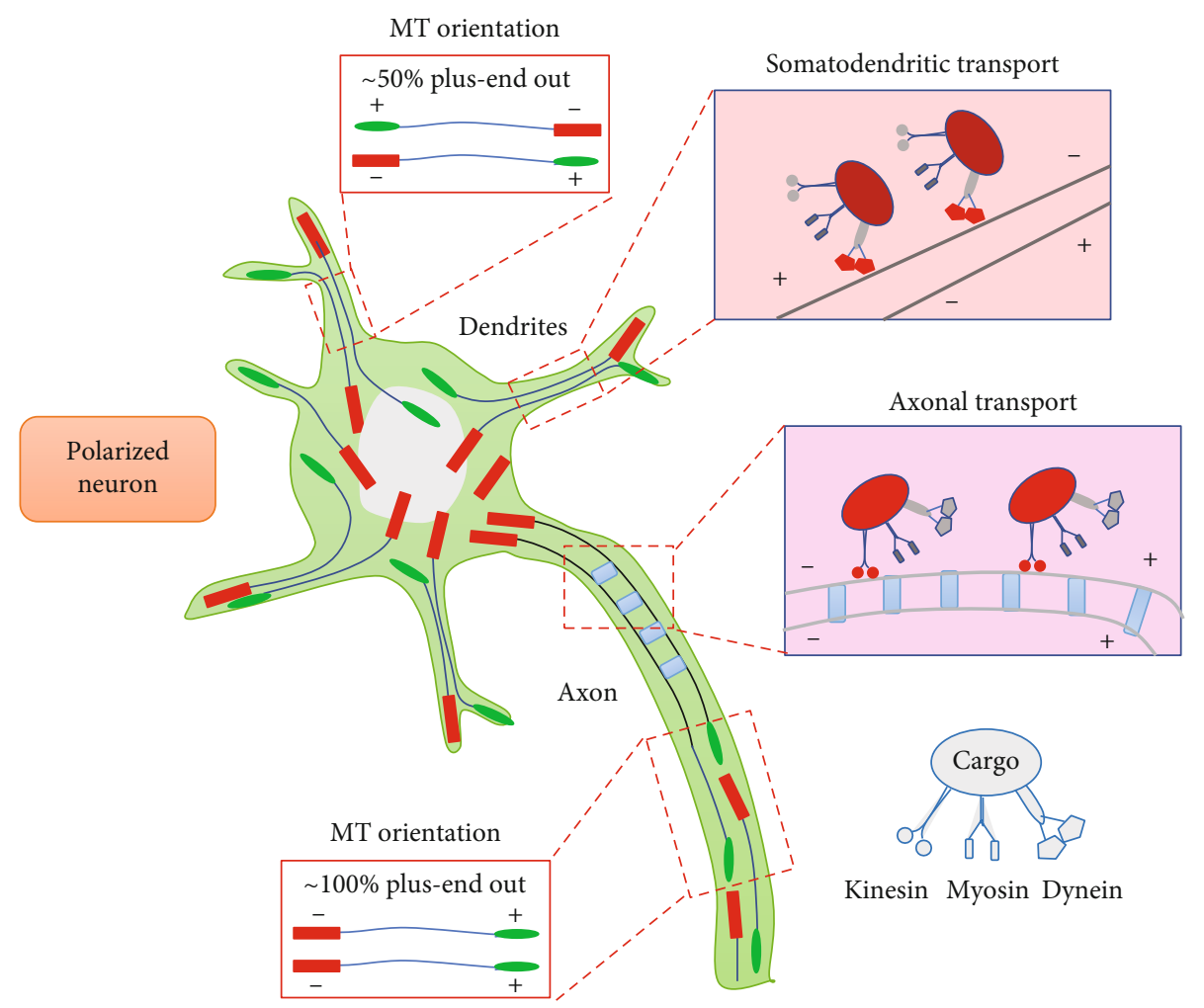

Figure 2: Basic mechanisms of MT organization during the differentiation of neurons into axons or dendrites. In axons, MTs display uniform polarity orientation with their plus-ends out. This array is essential to drive cargo transport through the proximal-end to the distal-end by kinesins, whereas in dendrites, MTs are mixed polarity with half of their minus-ends pointing to the soma, which allows dynein motors to selectively transport cargoes across this mixed MT arrays.

signaling cascades and for modulation by several molecules $[81,82]$. For instance, Shootin1 is a brain-specific cytoplasmic molecule that can be detected in the MT-associated protein fraction [83]. It is highly expressed in axonal growth cones and plays the central role for promoting neuronal polarity and axon outgrowth through a self-promoting feedback loop involving the Rac1/Pak1 signaling cascade [84, 85]. This facilitatory effect provides the driving force to induce one neurite under the growing state, while the remaining neurites are still in a pause state, ultimately driving neuron-autonomous neuronal polarization to generate a long signal-sending axon and several shorter signalreceiving dendrites.

\section{MT Modifications in Nervous System Injury}

Injury to the central nervous system (CNS) induces severe neurological complications for individuals with traumatic brain injury (TBI) or SCI because various inhibitory factors secreted by oligodendrocytes and scar-forming cells and the poor intrinsic growth ability upon neuronal maturation hamper axon regeneration and functional recovery [86, 87]. A growing number of studies have recently identified MTs as promising targets for coaxing regeneration of injured adult axons $[88,89]$. The functions of MTs include (1) providing a structural backbone to maintain axonspecialized morphologies [57], (2) acting as the major long-distance railways for substrate transport in both direc- tions [90], (3) ensuring the growth and steering of developing axons [91], and (4) regulating the extent of regeneration in injured axons [9]. Accordingly, moderate stabilization of MTs by Taxol enables MT polymerization and cytoskeleton organization, which transform the nongrowing retraction bulbs into growing axons [92]. Conversely, adding the MTdepolymerizing drug nocodazole to cultured dorsal root ganglia (DRG) neurons disturbs cytoskeleton organization and dynamics and increases the number of retraction bulbs [93].

TBI involves trauma to the CNS with characteristics of hypotension, hypoxia, and behavioral/cognitive abnormalities [94]. A common characteristic of TBI is loss of axonal integrity and cytoskeletal derangement, which are intrinsically associated with MT deficits and axonal dysfunction. Recently, MT disruption and loss, manifesting as MT depolymerization and the decrease of related proteins, such as Tau, p-Tau, and acetublin, were found to be key ultrastructural hallmarks of brain damage [95]. Thus, inducing MT stabilization is a novel therapeutic strategy to protect the damaged brain from high intracranial pressure and ischemia. A previous study reported that maintaining MT stabilization by local administration of FGF13 promoted neuronal migration and axon formation; in contrast, suppression of FGF13 expression delayed neuron migration and brain development [44]. Further studies revealed that administration of an MT-stabilizing drug, epothilone D, altered synaptic plasticity and dampened detrimental neuroglial responses 
after mild TBI of mice for 1 week [96]. However, intraperitoneal injections of low doses of exogenous nocodazole after TBI destroyed MT assembly and triggered a degenerative response characterized by loss of synapses and abnormal cytoskeletal rearrangement, as well as impairments in learning and memory [97]. While stabilizing the MT cytoskeleton is vital for ameliorating damage from TBI, there is still much to learn about the potential mechanisms involved in controlling this process.

SCI induces severe neurological deficits causing MT disorganization and deregulation of the MT cytoskeleton. Accumulating evidence has demonstrated that MT formation and stabilization are important for maintaining cytoskeletal integrity and axonal transport, as well as preventing detrimental gliotic responses [98]. Remodeling axonal MTs through genetic intervention or pharmacological treatment significantly enhanced axon regrowth and extension and reduced scar formation in an in vivo model of traumatic SCI, whereas the inhibition of MT stabilization by nocodazole weakens this beneficial effect [99]. Duan et al. demonstrated that systemic administration of epothilone B, an MT-stabilizing agent, reconstructed neovascularization by facilitating apoptosis and the migration of endothelial cells and pericytes and promoting their proliferation after SCI [100]. Moreover, regulation of MT dynamics by upregulating FGF13 expression is essential for promoting growth cone initiation, neuronal polarization, and regeneration of damaged axons following SCI [45]. Further studies found that MSAs also prevented fibroblast migration and prolonged the retention of MAPs, reducing inhibitory fibrotic scarring and improving intrinsic growth capacity, ultimately improving spinal cord restoration after injury [101-103]. In addition, recent studies on the relationship between autophagy and MT dynamics revealed that autophagy activation increased the expression of acetylated MT, a key modification for controlling MT stability and growth, thus attenuating axonal retraction and consequently enhancing locomotor recovery after SCI $[104,105]$. Overall, stabilizing MTs in damaged neuron plays a pivotal role in determining their regenerative capacity after SCI.

\section{MT-Targeting Agent}

MT-targeting agents can be classified into two main categories: MSAs and MDAs. The former, including paclitaxel, docetaxel, epothilones, and laulimalide, can bind to the tubulin heterodimer at the plus-end to promote the polymerization of tubulin to MTs. The latter induces MT dysfunction at the end of the mitotic spindle by preventing tubulin polymerization on both plus- and minus-ends of MT, leading to the arrest of mitosis. Representative examples of MDAs include vincristine, vinblastine, colchicine, and combretastatin. The regulatory mechanism by which MTtargeting agents influence MT dynamics depends on which MT domain they bind to [106] (Figure 3). According to their binding affinities to tubulin, these binding domains can be categorized as Taxol-binding domain, colchicine-binding domain, and vinca-binding domain [107]. MSAs are able to target the cytoskeleton and inhibit cell division by binding to $\beta$-tubulin of inner surface of MT lumen, which is generally described as the Taxol-binding domain [108]. Taxolbinding drugs, such as laulimalide, are shown to increase MT polymerization and assembly by allosterically stabilizing the Taxol-site M-loop [109]. MDAs depolymerize MTs by interacting with the vinca-binding domain or colchicine binding domain. Vincristine and vinblastine are two typical vinca-binding analogues. They induce mitotic arrest and block cell division by blocking tubulin polymerization at the interdimer interface, which is named the vincabinding domain [110]. Colchicine and combretastatin are colchicine-binding analogues. They bind to the Cys241 residue of $\beta$-tubulin (termed colchicine-binding domain) via hydrogen bonding to induce mitotic arrest and chromosome missegregation [111].

MT-targeting agents were traditionally used as anticancer agents for the treatment of various solid tumors [112]. To date, some of these agents are commonly approved for clinical anticancer chemotherapy for many types of solid tumors. However, recent work has shed light on their potential for treating traumatic nerve damage and neurodegenerative diseases, including Alzheimer's disease (AD), Parkinson's disease (PD), amyotrophic lateral sclerosis (ALS), and SCI (Table 1). This dual treatment ability aroused our curiosity. MTs are found in all characterized eukaryotic organisms, but exert diverse cellular functions in different cell types [113]. In cancer cells, MTs are one of the important components of the mitotic spindle and are capable of pulling sister chromatids towards opposite poles [114]. Thus, MT assembly and disassembly are critical for determining the proliferative capability of cancer cells. As mentioned in the previous passage, MT-targeting agents can interfere with the corresponding binding domains of tubulin to block their polymerization. This event impairs the ability of spindle MTs to capture chromosomes and interferes with the G2/M phase of the cell division, leading to mitotic arrest and even death in cancer cells [115]. In neurons, MTs, as one of the major longitudinal cytoskeletal filaments, are abundant in axons and dendrites [116]. Additionally, adult neurons or permanent differentiated neurons lack high proliferative capacity, resulting in few concerns and studies that are focused on MT-regulating neuronal division after damage or degeneration. Based on this fact, current studies are concentrated on the role of MT stability in regulating axon growth and steering as well as the intracellular trafficking of cargos during neuronal development $[9,116]$. Following neuronal injury or neurodegenerative diseases, MTs become disassembled and gradually lose mass, leading to axonal atrophy and degeneration [117]. MSAs, such as Taxol and epothilones, promote the polymerization of tubulin to MTs during disease and/or injury $[106,118]$. Thus, MSAs are regarded as potential candidates for treating neuronal disorders. However, the precise mechanism of MSAs for treating cancer and neuronal diseases needs to be explored in future research. In this section, we will introduce some background information on these therapeutic compounds and elucidate their application.

MSAs have been used as cancer therapeutic drugs for more than 20 years [130]. They were originally derived from 


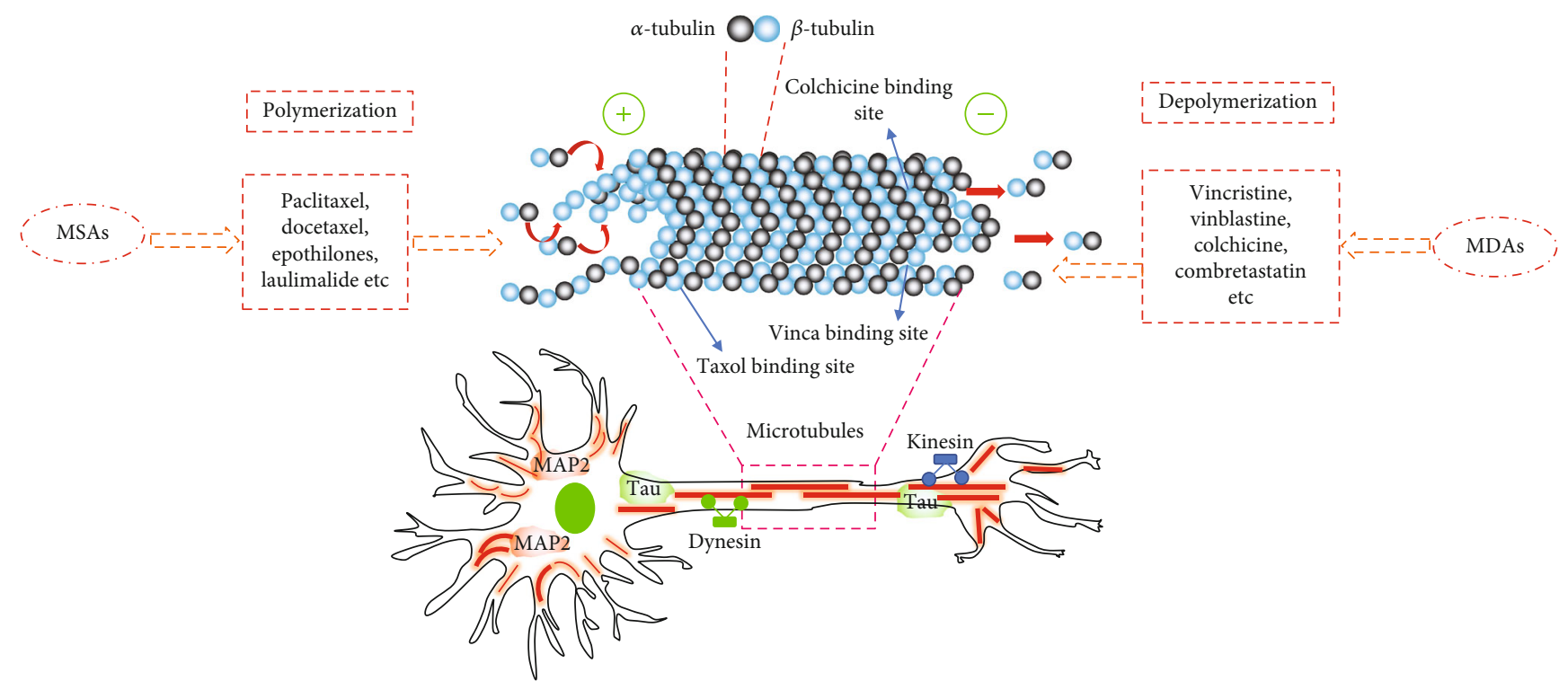

Figure 3: Diagram of MAPs, MSAs, and MDAs involved in the regulation of MT dynamics within neurons. MT organization and dynamics are regulated by MT proteins, MSAs and MDAs. MT-targeting agents can interfere with the dynamic equilibrium of MT polymerization and depolymerization. According to their mechanisms of action, MT-targeting agents can be divided into two groups: MSAs and MDAs. The former includes paclitaxel, docetaxel, epothilones, and laulimalide. They exert bind and interfere with the Taxol-binding domain and nontaxane sites. MDAs include vincristine, vinblastine, colchicine, and combretastatin. They depolymerize MTs by targeting the vincabinding domain and colchicine-binding domain. These MT-targeting agents influence the polymerization and depolymerization of MTs and are patterned by a variety of MAPs, including MAP2, Tau, dynein, and kinesin. These MAPs play the critical roles in mediating a plethora of cellular processes such as cell division and motility, intracellular transport, axonal specification, and neuronal development.

TABLE 1: Summary of various MT-targeting agents applied to protect the nervous system.

\begin{tabular}{|c|c|c|c|c|}
\hline Classification & Compound & Pathological model & Outcome & Ref. \\
\hline \multirow{7}{*}{ MSAs } & \multirow{3}{*}{$\begin{array}{l}\text { Paclitaxel } \\
\text { (Taxol) }\end{array}$} & SCI & Enhancement of nerve regeneration and functional recovery & {$[119,120]$} \\
\hline & & Retinal nerve injury & Increased MT numbers and stabilization to restore axonal transport & [121] \\
\hline & & $\mathrm{AD}$ & Improvements in axonal transport, tissue, and motor function & [122] \\
\hline & \multirow{3}{*}{ Epothilones } & SCI & $\begin{array}{c}\text { Decreased scarring, increased axon regeneration, and } \\
\text { improved motor function }\end{array}$ & {$[102,103]$} \\
\hline & & $\mathrm{PD}$ & Rescued MT defects and attenuated nigrostriatal degeneration & [123] \\
\hline & & $\mathrm{AD}$ & $\begin{array}{c}\text { Reduced axonal dystrophy, increased axonal MT density, } \\
\text { improved speed of axonal transport, and } \\
\text { improved cognitive performance }\end{array}$ & {$[124,125]$} \\
\hline & $\begin{array}{l}\text { Davunetide } \\
\text { (NAP) }\end{array}$ & $\mathrm{AD}, \mathrm{ALS}$ & $\begin{array}{l}\text { Prevented axonal transport disruption, synaptic } \\
\text { defects, and behavioral impairments }\end{array}$ & {$[126,127]$} \\
\hline \multirow{2}{*}{ MDAs } & Vincristine & $\begin{array}{l}\text { iPSC-derived neurons } \\
\text { from HSP patients }\end{array}$ & Ameliorated axonal swelling & {$[128]$} \\
\hline & $\begin{array}{l}\text { Okadaic } \\
\text { acid }\end{array}$ & $\begin{array}{l}\text { Hyperphosphorylated } \\
\text { Tau to model AD }\end{array}$ & Reduced the growth of the rat cortical neuron axons & [129] \\
\hline
\end{tabular}

natural resources. For instance, paclitaxel $\left(\operatorname{Taxol}^{\circledR}\right)$ was the first MSA to be isolated (derived from the Pacific yew tree in 1971) and approved by the FDA for the treatment of breast cancer, with an optimal therapeutic concentration of $260 \mathrm{mg} / \mathrm{m}^{2}$ [131]. This is decomposed into $6 \alpha$-hydroxy-paclitaxel by activating CYP2C8 enzyme in human liver microsomes [132]. Due to the difficulty of obtaining paclitaxel from the plant, various analogues, such as docetaxel, cabazitaxel, larotaxel, and TPI-287, have been synthesized through modification of its side chains and have exhibited encourag- ing clinical efficacy for treating breast cancer [133, 134]. Recent studies have shown that paclitaxel can maintain specialized neuronal morphology and support axonal and dendritic transport by resisting MT dynamic instability. For instance, Hellal et al. found that stabilizing the MT network with Taxol hindered the formation of scarring and prevented axonal retraction and swelling after SCI in rodents [119]. In another work, paclitaxel encapsulated in a collagen microchannel was shown to enhance neuronal differentiation of NSCs in vitro and improve axonal transport and 
axonal functional recovery in a complete spinal transsection injured models of rats [135].

Epothilones are another class of MSAs that include a 16membered macrocyclic lipid compound [136]. To date, six natural epothilone variants, i.e., epothilones A-F, can be easily obtained at a large scale by isolation from soil bacteria or by chemical synthesis [137]. Compared with paclitaxel, epothilones are more soluble in water and have better tumor resistance, which make them a viable alternative to paclitaxel in facilitating antitumor activity [138]. Data from phase III clinical trials revealed that ixabepilone, a semisynthetic analogue of epothilone $\mathrm{B}$, effectively improved the survival rate of patients with metastatic breast cancer to $70 \%$ with an intravenous infusion dose of $30 \mathrm{mg} / \mathrm{m}^{2}$ every 3 weeks [139]. In addition to treating cancer, a series of studies have shown that epothilones possess therapeutic potential for repairing neurological disorders. For instance, in a Tau transgenic mouse model of tauopathies characteristic of $\mathrm{AD}$, intraperitoneal injections of $3 \mathrm{mg} \mathrm{kg}^{-1}$ epothilone $\mathrm{D}$ once weekly for a 3-month period were demonstrated to support MT assembly and axon extension as well as reduce brain cognitive deficits [140]. In addition, this compound also exhibited beneficial effects on neuronal differentiation of cultured NSCs in vitro and improved axonal sprouting and functional recovery in vivo following SCI $[103,141]$. Additionally, epothilones are easier to administer than paclitaxel due to their higher water solubility, which endows epothilones with the capability to cross the blood-brain barrier [138]. In short, compared to paclitaxel, epothilones show several physicochemical advantages including (1) increased water solubility for direct delivery without solvent, (2) a lack of intracellular toxicity and strong antineoplastic activity, and (3) the capacity of easily crossing the bloodbrain barrier. In addition, the chemical structure of epothilones exhibits 16-membered macrocyclic lactones, which can produce synthetic analogues during clinical drug design [142]. It has been shown that systemic administration of epothilone B moderates MT stabilization to reduce fibrotic scarring and increase axon growth after SCI [102]. Additionally, epothilones augmented axonal growth and improved skilled limb function after cortical stroke in the brain [143]. Thus, both paclitaxel and epothilones are regarded as attractive therapeutic compounds for promoting the functional and structural recovery from neurodegenerative diseases and disorders.

MDAs, also called polymerizing inhibitors, possess the ability to promote the depolymerization of MTs by interfering with the colchicine-binding domain and vinca-binding domain to block cell division and interfere with the formation of a normal mitotic spindle. Thus, they have shown a strong antiangiogenic and antivascular activity and offer a pharmaceutical opportunity for treating different tumor types, including breast, lung, ovarian, and hematologic tumors [144]. According to their tubulin-binding domains, MDAs can be further divided into two groups: vincabinding analogues and colchicine-binding analogues [145]. The representative example in the former is vinca alkaloid (VA), a natural chemotherapy agent obtained from the Madagascar periwinkle plant in 1950. It was first approved by the FDA for the clinical treatment of lung cancer and breast cancer, but provoked severe neurotoxicity [146]. To overcome this defect, other VA analogues, including natural (vinblastine and vincristine) and semisynthetic (vinorelbine, vindesine, and vinflunine) analogues, have gained attracted attention in cancer treatment [147]. Data on clinical pharmacokinetics revealed that the terminal half-lives of VA and its derivatives range from 18 to $85 \mathrm{~h}$ [148]. Furthermore, they were found to be first metabolized within the liver through the action of cytochrome P450 CYP3A4 and then subjected to biliary elimination and finally excreted into the feces $[148,149]$. It should be addressed that VA and its derivatives can rapidly enter the peripheral tissues, including the peripheral nervous system; thus, administration of these antimitotic agents probably causes characteristic peripheral neurotoxicity [150]. To overcome this defect, researchers have identified three beneficial strategies to reduce these adverse effects, i.e., combination with other drugs, investigation of novel drug delivery platforms, and the synthesis of new VA analogues [147].

Colchicine, an alkaloid derived from the meadow saffron plant, belongs to the group of colchicine-binding analogues and is used as a therapeutic drug for anticancer treatment, such as lung, breast, and gynecological cancers [151]. Similar to VA metabolism, colchicine is broken down by the CYP3A4 enzyme within liver microsomes [152]. However, colchicine may cause toxicity in normal cell proliferation. A phase II clinical trial established that the safe dose of colchicine was $0.015 \mathrm{mg} \mathrm{kg}^{-1}$, a higher dose of $0.1 \mathrm{mg} \mathrm{kg}^{-1}$ resulted in intoxication, and the maximum fatal dose was $0.8 \mathrm{mg} \mathrm{kg}^{-1}$ [153-155]. Due to colchicine's low therapeutic index and severe cytotoxicity, various colchicine analogues have been synthesized by modifying the tricyclic-membered rings. Urbaniak et al. synthesized 16 novel colchicine derivatives, namely, double- (4-7) or triple-modified (17-28) urethanes, and found that these novel colchicine derivatives ( $\mathrm{IC}_{50}$ range of 1.1-6.4 $\mathrm{nM}$ ) had higher antiproliferative activity than colchicine $\left(\mathrm{IC}_{50}=8.6 \mathrm{nM}\right)$ by testing the viability of primary breast cancer cells [156]. Recently, the colchicine analogue combretastatin was found to promote anticancer activity by inhibiting the elongation of MTs [157]. Moreover, its synthetic derivatives show strong antioxidant activity and anti-inflammatory activity. For instance, Huang et al. demonstrated that the combretastatin derivatives NTU-228 and HK72 exhibited significant leukocyte inflammatory responses by quantifying N-formyl-Met-Leu-Phe- (fMLF-) induced reactive oxygen species production in human leukocytes [158]. Evidence from antioxidant studies in a subcutaneous dorsal CaNT tumor model revealed that combretastatin A-4, a combretastatin analogue, had strong protective effects against hydroxyl radicals and radical-based DNA damage [159].

\section{Concluding Remarks and Future Perspectives}

As briefly summarized here, MTs are dynamic cytoskeletal filaments that carry out the distinct functions of cellular physiology, such as cell division and motility, organelle positioning, and intracellular transport. Generally, MTs exhibit 
extensive dynamic instability, i.e., constant transition between phases of growing and shrinking. This allows them to enhance tubulin-tubulin interactions, create pushing and pulling forces, and direct cell locomotion via crosstalk with the actin cytoskeleton [160]. In vitro, the dynamic state of MTs can be recorded by measuring their rate of growth and shrinkage or by quantifying their mass [161]. The most common and reliable way to track MT dynamics is using high-resolution imaging methods, including fluorescent speckle microscopy and cryo-electron microscopy [162]. Additionally, MT acetylation is a common posttranslational modification that can protect MTs against mechanical stresses by polarizing the centrosome or the mitotic spindle within the cell [163]. Eliminating MT acetylation by reducing the activity of $\alpha$-tubulin acetyltransferase 1 enzyme does not impair protofilament organization but does cause a reduction in MT dynamics [164]. In brief, understanding the role of MT dynamics in cargo transportation and cytoskeletal reorganization has provided further insights into the biophysics and biochemistry of MT function involved in neuronal development, disease, and injury.

Given the importance of MT dynamics in cytoskeleton reconstruction, designing novel compounds that facilitate MT polymerization or upregulate MT acetylation has received increasing attention, due to the applications for different neurotraumatic diseases [57]. Encouragingly, some works have achieved positive therapeutic effects in cellular and animal models. For instance, systematic administration of epothilone B, a kind of MT-stabilizing agent, not only facilitated the growth of both sensory and motor axons in an unfavorable environment in vitro but also demonstrated dual effects on improving intrinsic neuron growth and reducing fibrotic scar in an in vivo SCI model [101, 102, 165]. While some natural MSAs can cause significant adverse side effects, including neutropenia, chemotherapyinduced peripheral neuropathy, and alopecia when used in cancer treatment at a high concentration [106, 166], researchers have proposed alternative and beneficial strategies, including synthesis of new MSA analogues, design of novel drug delivery platforms, and combinations with other drugs, to reduce these adverse effects [147]. Additionally, application of these therapeutic strategies can reduce the dosage of MSAs and their analogues; thus, administration at low concentrations can significantly enhance axonal regeneration and functional recovery in neuronal injury models. Further studies addressing the mechanisms that regulate the dynamic remodeling of MT networks will greatly increase our understanding of the intricacies of MT organization in various cell types.

$\begin{array}{ll}\text { Abbreviations } \\ \text { MT: } & \text { Microtubule } \\ \text { MTs: } & \text { Microtubules } \\ \text { MAPs: } & \text { Microtubule-associated proteins } \\ \text { MTAs: } & \text { Microtubule-targeting agents } \\ \gamma \text {-TuRC: } & \text { The gamma-tubulin ring complex } \\ \text { GCPs: } & \text { Gamma-tubulin complex proteins } \\ \text { MZT1: } & \text { Mitotic spindle organizing protein } 1\end{array}$

CM1: $\quad$ N-terminal centrosomin motif 1

MTOCs: Microtubule organizing centers

MAP: $\quad$ Microtubule-associated protein

DCX: Doublecortin

FGF13: Fibroblast growth factor 13

SCI: $\quad$ Spinal cord injury

CAMSAP: The calmodulin-regulated spectrin-associated protein

MSAs: Microtubule-stabilizing agents

MDAs: Microtubule-destabilizing agents

NSCs: Neural stem cells

CNS: $\quad$ The central nervous system

TBI: Traumatic brain injury

DRG: Dorsal root ganglia

AD: $\quad$ Alzheimer's disease

PD: $\quad$ Parkinson's disease

ALS: $\quad$ Amyotrophic lateral sclerosis

VA: $\quad$ Vinca alkaloid.

\section{Data Availability}

No new data are generated in this study.

\section{Conflicts of Interest}

The authors declare that they have no conflict of interest.

\section{Authors' Contributions}

H.L., T.X., and D.X. contributed in the validation, investigation, and data curation as well as in writing the manuscript. P.Y., L.R., J.Y., and Z.W. contributed in reviewing and editing the manuscript. All the authors read and approved the final manuscript.

\section{Acknowledgments}

This study was supported by a research grant from Medical and Health Science and Technology Project of Zhejiang Province (2019KY646 and 2020KY908), Science and Technology Project of Zhejiang Health Committee (2021KY1075), and the National Natural Science Funding of China (81802238).

\section{References}

[1] O. C. Rodriguez, A. W. Schaefer, C. A. Mandato, P. Forscher, W. M. Bement, and C. M. Waterman-Storer, "Conserved microtubule-actin interactions in cell movement and morphogenesis," Nature Cell Biology, vol. 5, no. 7, pp. 599-609, 2003.

[2] K. R. Navarrete and V. A. Jimenez, "Interdimeric Curvature in Tubulin-Tubulin Complexes Delineates the MicrotubuleDestabilizing Properties of Plocabulin," Journal of Chemical Information and Modeling, vol. 60, no. 8, pp. 4076-4084, 2020.

[3] J. Roostalu and T. Surrey, "Microtubule nucleation: beyond the template," Nature Reviews. Molecular Cell Biology, vol. 18, no. 11, pp. 702-710, 2017. 
[4] S. S. Parker, J. Krantz, E. A. Kwak et al., "Insulin induces microtubule stabilization and regulates the microtubule plusend tracking protein network in adipocytes* ${ }^{[\mathrm{S}]}$," Molecular \& cellular proteomics: MCP, vol. 18, no. 7, pp. 1363-1381, 2019.

[5] M. Vleugel, M. Kok, and M. Dogterom, "Understanding forcegenerating microtubule systems throughin vitroreconstitution," Cell Adhesion \& Migration, vol. 10, no. 5, pp. 475-494, 2016.

[6] P. Guedes-Dias and E. L. F. Holzbaur, "Axonal transport: driving synaptic function,” Science, vol. 366, no. 6462, article eaaw9997, 2019.

[7] A. Valenzuela, L. Meservey, H. Nguyen, and M. M. Fu, “Golgi outposts nucleate microtubules in cells with specialized shapes," Trends in Cell Biology, vol. 30, no. 10, pp. 792-804, 2020.

[8] R. P. Tas, A. Chazeau, B. M. C. Cloin, M. L. A. Lambers, C. C. Hoogenraad, and L. C. Kapitein, "Differentiation between oppositely oriented microtubules controls polarized neuronal transport," Neuron, vol. 96, no. 6, article e1265, pp. 12641271, 2017.

[9] M. M. Rolls, P. Thyagarajan, and C. Feng, "Microtubule dynamics in healthy and injured neurons," Developmental Neurobiology, vol. 81, no. 3, pp. 321-332, 2021.

[10] F. Marchisella, E. T. Coffey, and P. Hollos, "Microtubule and microtubule associated protein anomalies in psychiatric disease," Cytoskeleton, vol. 73, no. 10, pp. 596-611, 2016.

[11] A. Desai and T. J. Mitchison, "Microtubule polymerization dynamics," Annual Review of Cell and Developmental Biology, vol. 13, no. 1, pp. 83-117, 1997.

[12] T. Horio and T. Murata, "The role of dynamic instability in microtubule organization," Frontiers in Plant Science, vol. 5, article 511, 2014.

[13] L. Penazzi, L. Bakota, and R. Brandt, "Microtubule dynamics in neuronal development, plasticity, and neurodegeneration," International Review of Cell and Molecular Biology, vol. 321, pp. 89-169, 2016.

[14] E. W. Dent, "Of microtubules and memory: implications for microtubule dynamics in dendrites and spines," Molecular Biology of the Cell, vol. 28, no. 1, pp. 1-8, 2017.

[15] R. Heald and E. Nogales, "Microtubule dynamics," Journal of Cell Science, vol. 115, no. 1, pp. 3-4, 2002.

[16] A. C. Schmit, E. Herzog, and M. E. Chaboute, "GIP/MZT1 proteins: key players in centromere regulation," Cell Cycle, vol. 14, no. 23, pp. 3665-3666, 2015.

[17] C. A. Tovey and P. T. Conduit, "Microtubule nucleation by $\gamma$ tubulin complexes and beyond," Essays in Biochemistry, vol. 62, no. 6, pp. 765-780, 2018.

[18] P. Liu, M. Wurtz, E. Zupa, S. Pfeffer, and E. Schiebel, "Microtubule nucleation: The waltz between $\gamma$-tubulin ring complex and associated proteins," Current Opinion in Cell Biology, vol. 68, pp. 124-131, 2021.

[19] S. L. Leong, E. M. Lynch, J. Zou et al., "Reconstitution of microtubule nucleation in vitro reveals novel roles for Mzt1," Current Biology, vol. 29, no. 13, article e2110, pp. 2199-2207, 2019.

[20] H. V. Goodson and E. M. Jonasson, "Microtubules and microtubule-associated proteins," Cold Spring Harbor perspectives in biology, vol. 10, no. 6, article a022608, 2018.

[21] K. K. Gupta, C. Li, A. Duan et al., "Mechanism for the catastrophe-promoting activity of the microtubule destabilizer Op18/stathmin," Proceedings of the National Academy of Sciences of the United States of America, vol. 110, no. 51, pp. 20449-20454, 2013.

[22] P. Ayaz, S. Munyoki, E. A. Geyer et al., "A tethered delivery mechanism explains the catalytic action of a microtubule polymerase," Elife, vol. 3, article e03069, 2014.

[23] J. Olah, A. Lehotzky, S. Szunyogh, T. Szenasi, F. Orosz, and J. Ovadi, "Microtubule-associated proteins with regulatory functions by day and pathological potency at night," Cells, vol. 9, no. 2, article 357, 2020.

[24] Y. Ruan, L. S. Halat, D. Khan et al., "The microtubuleassociated protein CLASP sustains cell proliferation through a brassinosteroid signaling negative feedback loop," Current Biology, vol. 28, no. 17, article e2715, pp. 2718-2729, 2018.

[25] Y. Fan, G. M. Burkart, and R. Dixit, "The arabidopsis SPIRAL2 protein targets and stabilizes microtubule minus ends," Current Biology, vol. 28, no. 6, article e983, pp. 987-994, 2018.

[26] L. Dehmelt and S. Halpain, "The MAP2/Tau family of microtubule-associated proteins," Genome Biology, vol. 6, no. 1, article 204, 2005.

[27] J. Zhang, R. W. M. Min, K. Le et al., "The role of MAP2 kinases and p38 kinase in acute murine liver injury models," Cell Death \& Disease, vol. 8, no. 6, article e2903, 2017.

[28] L. F. Gumy, E. A. Katrukha, I. Grigoriev et al., "MAP2 defines a pre-axonal filtering zone to regulate KIF1- versus KIF5dependent cargo transport in sensory neurons," Neuron, vol. 94, no. 2, article e347, pp. 347-362, 2017.

[29] K. Melkova, V. Zapletal, S. Narasimhan et al., "Structure and functions of microtubule associated proteins Tau and MAP2c: similarities and differences," Biomolecules, vol. 9, no. 3, article 105, 2019.

[30] R. Brandt, N. I. Trushina, and L. Bakota, "Much more than a sytoskeletal protein: physiological and pathological functions of the non-microtubule binding region of Tau," Frontiers in Neurology, vol. 11, article 12691269, 2020.

[31] R. L. Mueller, B. Combs, M. M. Alhadidy, S. T. Brady, G. A. Morfini, and N. M. Kanaan, "Tau: a signaling hub protein," Frontiers in Molecular Neuroscience, vol. 14, article 647054, 2021.

[32] B. Caballero, M. Bourdenx, E. Luengo et al., "Acetylated tau inhibits chaperone-mediated autophagy and promotes tau pathology propagation in mice," Nature Communications, vol. \, no. 1, article 2238, 2021.

[33] D. Janning, M. Igaev, F. Sundermann et al., "Single-molecule tracking of tau reveals fast kiss-and-hop interaction with microtubules in living neurons," Molecular Biology of the Cell, vol. 25, no. 22, pp. 3541-3551, 2014.

[34] N. I. Trushina, L. Bakota, A. Y. Mulkidjanian, and R. Brandt, "The evolution of Tau phosphorylation and interactions," Frontiers in aging Neuroscience, vol. 11, article 256, 2019.

[35] H. Kadavath, R. V. Hofele, J. Biernat et al., "Tau stabilizes microtubules by binding at the interface between tubulin heterodimers," Proceedings of the National Academy of Sciences of the United States of America, vol. 112, no. 24, pp. 75017506, 2015.

[36] Y. Okada and N. Hirokawa, "Mechanism of the singleheaded processivity: diffusional anchoring between the Kloop of kinesin and the C terminus of tubulin," Proceedings of the National Academy of Sciences of the United States of America, vol. 97, no. 2, pp. 640-645, 2000. 
[37] S. Wegmann, J. Biernat, and E. Mandelkow, "A current view on Tau protein phosphorylation in Alzheimer's disease," Current Opinion in Neurobiology, vol. 69, pp. 131-138, 2021.

[38] L. Wang, F. X. Shi, N. Li et al., "AMPK ameliorates tau acetylation and memory impairment through Sirt1," Molecular Neurobiology, vol. 57, no. 12, pp. 5011-5025, 2020.

[39] B. Klein, H. Mrowetz, C. Kreutzer et al., "DCX(+) neuronal progenitors contribute to new oligodendrocytes during remyelination in the hippocampus," Scientific Reports, vol. 10, no. 1, article 20095, 2020.

[40] J. Dhaliwal, Y. Xi, E. Bruel-Jungerman, J. Germain, F. Francis, and D. C. Lagace, "Doublecortin (DCX) is not essential for survival and differentiation of newborn neurons in the adult mouse dentate gyrus," Frontiers in Neuroscience, vol. 9, article 494, 2015.

[41] C. J. Bott, L. P. McMahon, J. M. Keil, C. C. Yap, K. Y. Kwan, and B. Winckler, "Nestin selectively facilitates the phosphorylation of the lissencephaly-linked protein doublecortin (DCX) by cdk5/p35 to regulate growth cone morphology and Sema3a sensitivity in developing neurons," The Journal of neuroscience : the official journal of the Society for Neuroscience, vol. 40, no. 19, pp. 3720-3740, 2020.

[42] T. Pramparo, Y. H. Youn, J. Yingling, S. Hirotsune, and A. Wynshaw-Boris, "Novel embryonic neuronal migration and proliferation defects in Dcx mutant mice are exacerbated by Lis1 reduction," The Journal of neuroscience : the official journal of the Society for Neuroscience, vol. 30, no. 8, pp. 3002-3012, 2010.

[43] E. Q. Wei, D. S. Sinden, L. Mao, H. Zhang, C. Wang, and G. S. Pitt, "Inducible Fgf13 ablation enhances caveolae-mediated cardioprotection during cardiac pressure overload," Proceedings of the National Academy of Sciences of the United States of America, vol. 114, no. 20, pp. E4010-E4019, 2017.

[44] Q. F. Wu, L. Yang, S. Li et al., "Fibroblast growth factor 13 is a microtubule-stabilizing protein regulating neuronal polarization and migration," Cell, vol. 149, no. 7, pp. 1549-1564, 2012.

[45] J. Li, Q. Wang, H. Wang et al., "Lentivirus mediating FGF13 enhances axon regeneration after spinal cord injury by stabilizing microtubule and improving mitochondrial function," Journal of Neurotrauma, vol. 35, no. 3, pp. 548-559, 2018.

[46] J. Atherton, Y. Luo, S. Xiang et al., "Structural determinants of microtubule minus end preference in CAMSAP CKK domains," Nature Communications, vol. 10, no. 1, article 5236, 2019.

[47] K. Vukusic, I. Ponjavic, R. Buda, P. Risteski, and I. M. Tolic, "Microtubule-sliding modules based on kinesins EG5 and PRC1-dependent KIF4A drive human spindle elongation," Developmental Cell, vol. 56, no. 9, article e1210, pp. 12531267, 2021.

[48] M. K. Gardner, M. Zanic, C. Gell, V. Bormuth, and J. Howard, "Depolymerizing kinesins Kip3 and MCAK shape cellular microtubule architecture by differential control of catastrophe," Cell, vol. 147, no. 5, pp. 1092-1103, 2011.

[49] A. Mitra, F. Ruhnow, S. Girardo, and S. Diez, "Directionally biased sidestepping of Kip3/kinesin- 8 is regulated by ATP waiting time and motor-microtubule interaction strength," Proceedings of the National Academy of Sciences of the United States of America, vol. 115, no. 34, pp. E7950-E7959, 2018.

[50] Y. J. Liang and W. X. Yang, "Kinesins in MAPK cascade: how kinesin motors are involved in the MAPK pathway?," Gene, vol. 684, pp. 1-9, 2019.
[51] K. C. McNeely, T. D. Cupp, J. N. Little, K. M. Janisch, A. Shrestha, and N. D. Dwyer, "Mutation of kinesin-6 Kif20b causes defects in cortical neuron polarization and morphogenesis," Neural Development, vol. 12, no. 1, article 684, pp. 1-9, 2017.

[52] A. Akhmanova and M. O. Steinmetz, "Microtubule minusend regulation at a glance," Journal of Cell Science, vol. 132, no. 11, article jcs227850, 2019.

[53] M. C. Hendershott and R. D. Vale, "Regulation of microtubule minus-end dynamics by CAMSAPs and Patronin," Proceedings of the National Academy of Sciences of the United States of America, vol. 111, no. 16, pp. 5860-5865, 2014.

[54] A. Akhmanova and C. C. Hoogenraad, "Microtubule minusend-targeting proteins," Current Biology : CB, vol. 25, no. 4, pp. R162-R171, 2015.

[55] Y. Cao, J. Lipka, R. Stucchi et al., "Microtubule minus-end binding protein CAMSAP2 and kinesin-14 motor KIFC3 control dendritic microtubule organization," Current Biology, vol. 30, no. 5, article e896, pp. 899-908, 2020.

[56] V. Pongrakhananon, H. Saito, S. Hiver et al., "CAMSAP3 maintains neuronal polarity through regulation of microtubule stability," Proceedings of the National Academy of Sciences of the United States of America, vol. 115, no. 39, pp. 9750-9755, 2018.

[57] P. W. Baas, A. N. Rao, A. J. Matamoros, and L. Leo, "Stability properties of neuronal microtubules," Cytoskeleton, vol. 73, no. 9, pp. 442-460, 2016.

[58] P. Kratsios and O. Hobert, "Nervous system development: flies and worms converging on neuron identity control," Current biology : $C B$, vol. 28, no. 19, pp. R1154-R1157, 2018.

[59] M. Schelski and F. Bradke, "Neuronal polarization: from spatiotemporal signaling to cytoskeletal dynamics," Molecular and Cellular Neurosciences, vol. 84, pp. 11-28, 2017.

[60] C. G. Dotti, C. A. Sullivan, and G. A. Banker, "The establishment of polarity by hippocampal neurons in culture," The Journal of neuroscience: the official journal of the Society for Neuroscience, vol. 8, no. 4, pp. 1454-1468, 1988.

[61] X. Liang, M. Kokes, R. D. Fetter et al., "Growth cone-localized microtubule organizing center establishes microtubule orientation in dendrites," Elife, vol. 9, article e56547, 2020.

[62] P. R. Gordon-Weeks, "Microtubules and growth cone function," Journal of Neurobiology, vol. 58, no. 1, pp. 70-83, 2004.

[63] O. F. Omotade, S. L. Pollitt, and J. Q. Zheng, "Actin-based growth cone motility and guidance," Molecular and Cellular Neurosciences, vol. 84, pp. 4-10, 2017.

[64] T. D. Pollard, "New Light on Growth Cone Navigation," Developmental Cell, vol. 35, no. 6, pp. 672-673, 2015.

[65] Y. Zou, "Breaking symmetry - cell polarity signaling pathways in growth cone guidance and synapse formation," Current Opinion in Neurobiology, vol. 63, pp. 77-86, 2020.

[66] E. S. Chhabra and H. N. Higgs, "The many faces of actin: matching assembly factors with cellular structures," Nature Cell Biology, vol. 9, no. 10, pp. 1110-1121, 2007.

[67] S. Geraldo and P. R. Gordon-Weeks, "Cytoskeletal dynamics in growth-cone steering," Journal of Cell Science, vol. 122, no. 20, pp. 3595-3604, 2009.

[68] J. Round and E. Stein, "Netrin signaling leading to directed growth cone steering," Current Opinion in Neurobiology, vol. 17, no. 1, pp. 15-21, 2007. 
[69] M. T. Kelliher, H. A. Saunders, and J. Wildonger, "Microtubule control of functional architecture in neurons," Current Opinion in Neurobiology, vol. 57, pp. 39-45, 2019.

[70] E. M. Craig, H. T. Yeung, A. N. Rao, and P. W. Baas, "Polarity sorting of axonal microtubules: a computational study," Molecular Biology of the Cell, vol. 28, no. 23, pp. 3271-3285, 2017.

[71] W. Lu and V. I. Gelfand, "Moonlighting motors: kinesin, dynein, and cell polarity," Trends in Cell Biology, vol. 27, no. 7, pp. 505-514, 2017.

[72] G. Bhabha, G. T. Johnson, C. M. Schroeder, and R. D. Vale, "How dynein moves along microtubules," Trends in Biochemical Sciences, vol. 41, no. 1, pp. 94-105, 2016.

[73] N. Hirokawa, S. Niwa, and Y. Tanaka, "Molecular motors in neurons: transport mechanisms and roles in brain function, development, and disease," Neuron, vol. 68, no. 4, pp. 610638, 2010.

[74] S. F. van Beuningen and C. C. Hoogenraad, "Neuronal polarity: remodeling microtubule organization," Current Opinion in Neurobiology, vol. 39, pp. 1-7, 2016.

[75] O. R. Wilkes and A. W. Moore, "Distinct microtubule organizing center mechanisms combine to generate neuron polarity and arbor complexity," Frontiers in Cellular Neuroscience, vol. 14, article 594199, 2020.

[76] T. Y. Eom, A. Stanco, J. Guo et al., "Differential regulation of microtubule severing by APC underlies distinct patterns of projection neuron and interneuron migration," Developmental Cell, vol. 31, no. 6, pp. 677-689, 2014.

[77] X. Xie, S. Wang, M. Li et al., "alpha-TubK40me3 is required for neuronal polarization and migration by promoting microtubule formation," Nature Communications, vol. 12, no. 1 , article 4113, 2021.

[78] D. Seetapun and D. J. Odde, "Cell-length-dependent microtubule accumulation during polarization," Current biology : $C B$, vol. 20, no. 11, pp. 979-988, 2010.

[79] T. Namba, Y. Funahashi, S. Nakamuta, C. Xu, T. Takano, and K. Kaibuchi, "Extracellular and intracellular signaling for neuronal polarity," Physiological Reviews, vol. 95, no. 3, pp. 995-1024, 2015.

[80] H. Witte and F. Bradke, "The role of the cytoskeleton during neuronal polarization," Current Opinion in Neurobiology, vol. 18, no. 5, pp. 479-487, 2008.

[81] S. M. Hapak, S. Ghosh, and C. V. Rothlin, "Axon regeneration: antagonistic signaling pairs in neuronal polarization," Trends in Molecular Medicine, vol. 24, no. 7, pp. 615-629, 2018.

[82] S. Gomis-Ruth, C. J. Wierenga, and F. Bradke, "Plasticity of polarization: changing dendrites into axons in neurons integrated in neuronal circuits," Current biology : $C B$, vol. 18, no. 13, pp. 992-1000, 2008.

[83] M. Toriyama, S. Kozawa, Y. Sakumura, and N. Inagaki, "Conversion of a signal into forces for axon outgrowth through Pak1-mediated shootin1 phosphorylation," Current biology: $C B$, vol. 23, no. 6, pp. 529-534, 2013.

[84] T. Sapir, T. Levy, A. Sakakibara, A. Rabinkov, T. Miyata, and O. Reiner, "Shootin1 acts in concert with KIF20B to promote polarization of migrating neurons," The Journal of neuroscience : the official journal of the Society for Neuroscience, vol. 33, no. 29, pp. 11932-11948, 2013.

[85] Y. Kubo, K. Baba, M. Toriyama et al., "Shootin1-cortactin interaction mediates signal-force transduction for axon out- growth," The Journal of Cell Biology, vol. 210, no. 4, pp. 663-676, 2015.

[86] A. Capizzi, J. Woo, and M. Verduzco-Gutierrez, "Traumatic brain injury: an overview of epidemiology, pathophysiology, and medical management," The Medical Clinics of North America, vol. 104, no. 2, pp. 213-238, 2020.

[87] B. Fan, Z. Wei, X. Yao et al., "Microenvironment imbalance of spinal cord injury," Cell Transplantation, vol. 27, no. 6, pp. 853-866, 2018.

[88] G. Liu and T. Dwyer, "Microtubule dynamics in axon guidance," Neuroscience Bulletin, vol. 30, no. 4, pp. 569-583, 2014.

[89] I. Hahn, A. Voelzmann, Y. T. Liew, B. Costa-Gomes, and A. Prokop, "The model of local axon homeostasis - explaining the role and regulation of microtubule bundles in axon maintenance and pathology," Neural Development, vol. 14, no. 1, pp. 1-28, 2019.

[90] O. Blanquie and F. Bradke, "Cytoskeleton dynamics in axon regeneration," Current Opinion in Neurobiology, vol. 51, pp. 60-69, 2018.

[91] A. Kumari and D. Panda, "Regulation of microtubule stability by centrosomal proteins," IUBMB Life, vol. 70, no. 7, pp. 602611, 2018.

[92] A. Erturk, F. Hellal, J. Enes, and F. Bradke, "Disorganized microtubules underlie the formation of retraction bulbs and the failure of axonal regeneration," The Journal of neuroscience : the official journal of the Society for Neuroscience, vol. 27, no. 34, pp. 9169-9180, 2007.

[93] Z. Xu, L. Schaedel, D. Portran et al., "Microtubules acquire resistance from mechanical breakage through intralumenal acetylation," Science, vol. 356, no. 6335, pp. 328-332, 2017.

[94] D. Najem, K. Rennie, M. Ribecco-Lutkiewicz et al., "Traumatic brain injury: classification, models, and markers," Biochemistry and Cell Biology = Biochimie et biologie cellulaire, vol. 96, no. 4, pp. 391-406, 2018.

[95] R. Rubenstein, B. Chang, J. K. Yue et al., "Comparing plasma phospho tau, total tau, and phospho tau-total tau ratio as acute and chronic traumatic brain injury biomarkers," JAMA Neurology, vol. 74, no. 9, pp. 1063-1072, 2017.

[96] J. A. Chuckowree, Z. Zhu, M. Brizuela, K. M. Lee, C. A. Blizzard, and T. C. Dickson, "The microtubule-modulating drug epothilone D alters dendritic spine morphology in a mouse model of mild traumatic brain injury," Frontiers in Cellular Neuroscience, vol. 12, article 223, 2018.

[97] Y. C. Yap, A. E. King, R. M. Guijt et al., "Mild and repetitive very mild axonal stretch injury triggers cystoskeletal mislocalization and growth cone collapse," PloS One, vol. 12, no. 5, article e0176997, 2017.

[98] J. M. Griffin and F. Bradke, "Therapeutic repair for spinal cord injury: combinatory approaches to address a multifaceted problem," EMBO Molecular Medicine, vol. 12, no. 3, article e11505, 2020.

[99] H. de Forges, A. Bouissou, and F. Perez, "Interplay between microtubule dynamics and intracellular organization," The International Journal of Biochemistry \& Cell Biology, vol. 44, no. 2, pp. 266-274, 2012.

[100] Y. Y. Duan, Y. Chai, N. L. Zhang, D. M. Zhao, and C. Yang, "Microtubule stabilization promotes microcirculation reconstruction after spinal cord injury," Journal of molecular neuroscience : $M N$, vol. 71, no. 3, pp. 583-595, 2021.

[101] J. Ruschel and F. Bradke, "Systemic administration of epothilone $\mathrm{D}$ improves functional recovery of walking after rat 
spinal cord contusion injury," Experimental Neurology, vol. 306, pp. 243-249, 2018.

[102] J. Ruschel, F. Hellal, K. C. Flynn et al., "Systemic administration of epothilone B promotes axon regeneration after spinal cord injury," Science, vol. 348, no. 6232, pp. 347-352, 2015.

[103] B. Sandner, R. Puttagunta, M. Motsch et al., "Systemic epothilone D improves hindlimb function after spinal cord contusion injury in rats," Experimental Neurology, vol. 306, pp. 250-259, 2018.

[104] M. He, Y. Ding, C. Chu, J. Tang, Q. Xiao, and Z. G. Luo, "Autophagy induction stabilizes microtubules and promotes axon regeneration after spinal cord injury," Proceedings of the National Academy of Sciences of the United States of America, vol. 113, no. 40, pp. 11324-11329, 2016.

[105] Y. Rong, W. Liu, J. Wang et al., "Neural stem cell-derived small extracellular vesicles attenuate apoptosis and neuroinflammation after traumatic spinal cord injury by activating autophagy," Cell Death \& Disease, vol. 10, no. 5, pp. 1-18, 2019.

[106] F. Naaz, M. R. Haider, S. Shafi, and M. S. Yar, “Anti-tubulin agents of natural origin: targeting taxol, vinca, and colchicine binding domains," European Journal of Medicinal Chemistry, vol. 171, pp. 310-331, 2019.

[107] D. Cao, Y. Liu, W. Yan et al., "Design, synthesis, and evaluation of in vitro and in vivo anticancer activity of 4-substituted coumarins: a novel class of potent tubulin polymerization inhibitors," Journal of Medicinal Chemistry, vol. 59, no. 12, pp. 5721-5739, 2016.

[108] K. H. Altmann, "Microtubule-stabilizing agents: a growing class of important anticancer drugs," Current Opinion in Chemical Biology, vol. 5, no. 4, pp. 424-431, 2001.

[109] L. A. Amos, "Microtubule structure and its stabilisation," Organic \& Biomolecular Chemistry, vol. 2, no. 15, pp. 21532160, 2004.

[110] S. Florian and T. J. Mitchison, “Anti-microtubule drugs," The Mitotic Spindle, vol. 1413, pp. 403-421, 2016.

[111] J. Bennouna, J. P. Delord, M. Campone, and L. Nguyen, "Vinflunine: a new microtubule inhibitor agent," Clinical cancer research: an official journal of the American Association for Cancer Research, vol. 14, no. 6, pp. 1625-1632, 2008.

[112] A. E. Prota, K. Bargsten, D. Zurwerra et al., "Molecular mechanism of action of microtubule-stabilizing anticancer agents," Science, vol. 339, no. 6119, pp. 587-590, 2013.

[113] A. Akhmanova and M. O. Steinmetz, "Control of microtubule organization and dynamics: two ends in the limelight," Nature Reviews. Molecular Cell Biology, vol. 16, no. 12, pp. 711-726, 2015.

[114] D. Fanale, G. Bronte, F. Passiglia et al., "Stabilizing versus destabilizing the microtubules: a double-edge sword for an effective cancer treatment option?," Analytical Cellular Pathology, vol. 2015, Article ID 690916, 19 pages, 2015.

[115] J. J. Field, A. Kanakkanthara, and J. H. Miller, "Microtubuletargeting agents are clinically successful due to both mitotic and interphase impairment of microtubule function," Bioorganic \& Medicinal Chemistry, vol. 22, no. 18, pp. 50505059, 2014.

[116] L. C. Kapitein and C. C. Hoogenraad, "Building the neuronal microtubule cytoskeleton,” Neuron, vol. 87, no. 3, pp. 492506, 2015.

[117] A. Sferra, F. Nicita, and E. Bertini, "Microtubule dysfunction: a common feature of neurodegenerative diseases," Interna- tional journal of molecular sciences, vol. 21, no. 19, article 7354, 2020.

[118] R. Altaha, T. Fojo, E. Reed, and J. Abraham, "Epothilones: a novel class of non-taxane microtubule-stabilizing agents," Current Pharmaceutical Design, vol. 8, no. 19, pp. 17071712, 2002.

[119] F. Hellal, A. Hurtado, J. Ruschel et al., "Microtubule stabilization reduces scarring and causes axon regeneration after spinal cord injury," Science, vol. 331, no. 6019, pp. 928-931, 2011.

[120] P. G. Popovich, C. A. Tovar, S. Lemeshow, Q. Yin, and L. B. Jakeman, "Independent evaluation of the anatomical and behavioral effects of Taxol in rat models of spinal cord injury," Experimental Neurology, vol. 261, pp. 97-108, 2014.

[121] V. Sengottuvel, M. Leibinger, M. Pfreimer, A. Andreadaki, and D. Fischer, "Taxol facilitates axon regeneration in the mature CNS," The Journal of neuroscience: the official journal of the Society for Neuroscience, vol. 31, no. 7, pp. 2688-2699, 2011.

[122] A. R. Duan and H. V. Goodson, "Taxol-stabilized microtubules promote the formation of filaments from unmodified full-length tau in vitro," Molecular Biology of the Cell, vol. 23, no. 24, pp. 4796-4806, 2012.

[123] D. Cartelli, F. Casagrande, C. L. Busceti et al., "Microtubule alterations occur early in experimental parkinsonism and the microtubule stabilizer epothilone D is neuroprotective," Scientific Reports, vol. 3, article 1837, pp. 1-10, 2013.

[124] B. Zhang, J. Carroll, J. Q. Trojanowski et al., "The microtubule-stabilizing agent, epothilone $\mathrm{D}$, reduces axonal dysfunction, neurotoxicity, cognitive deficits, and Alzheimer-like pathology in an interventional study with aged tau transgenic mice," The Journal of neuroscience : the official journal of the Society for Neuroscience, vol. 32, no. 11, pp. 3601-3611, 2012.

[125] P. Mondal, G. Das, J. Khan, K. Pradhan, and S. Ghosh, "Crafting of neuroprotective octapeptide from taxol-binding pocket of $\beta$-tubulin," ACS Chemical Neuroscience, vol. 9, no. 3, pp. 615-625, 2018.

[126] S. Quraishe, C. M. Cowan, and A. Mudher, "NAP (davunetide) rescues neuronal dysfunction in a Drosophila model of tauopathy," Molecular Psychiatry, vol. 18, no. 7, pp. 834$842,2013$.

[127] I. Magen and I. Gozes, "Microtubule-stabilizing peptides and small molecules protecting axonal transport and brain function: focus on davunetide (NAP)," Neuropeptides, vol. 47, no. 6, pp. 489-495, 2013.

[128] C. Schinke, V. Fernandez Vallone, A. Ivanov et al., "Modeling chemotherapy induced neurotoxicity with human induced pluripotent stem cell (iPSC) -derived sensory neurons," Neurobiology of Disease, vol. 155, article 105391, 2021.

[129] V. Das and J. H. Miller, "Microtubule stabilization by peloruside A and paclitaxel rescues degenerating neurons from okadaic acid-induced tau phosphorylation," The European Journal of Neuroscience, vol. 35, no. 11, pp. 1705-1717, 2012.

[130] Y. Zhao, X. Mu, and G. Du, "Microtubule-stabilizing agents: new drug discovery and cancer therapy," Pharmacology \& Therapeutics, vol. 162, pp. 134-143, 2016.

[131] M. N. Kundranda and J. Niu, "Albumin-bound paclitaxel in solid tumors: clinical development and future directions," Drug Design, Development and Therapy, vol. 9, pp. 37673777, 2015. 
[132] M. Joerger, "Metabolism of the taxanes including nab-paclitaxel," Expert Opinion on Drug Metabolism \& Toxicology, vol. 11, no. 5, pp. 691-702, 2015.

[133] N. I. Marupudi, J. E. Han, K. W. Li, V. M. Renard, B. M. Tyler, and H. Brem, "Paclitaxel: a review of adverse toxicities and novel delivery strategies," Expert Opinion on Drug Safety, vol. 6, no. 5, pp. 609-621, 2007.

[134] L. Zhu and L. Chen, "Progress in research on paclitaxel and tumor immunotherapy," Cellular \& Molecular Biology Letters, vol. 24, no. 1, pp. 1-11, 2019.

[135] X. Li, C. Fan, Z. Xiao et al., "A collagen microchannel scaffold carrying paclitaxel-liposomes induces neuronal differentiation of neural stem cells through $\mathrm{Wnt} / \beta$-catenin signaling for spinal cord injury repair," Biomaterials, vol. 183, pp. 114-127, 2018.

[136] J. Mulzer and K. Prantz, "Total synthesis of epothilones AF," in The Epothilones: An Outstanding Family of Anti-Tumor Agents, pp. 55-133, Springer, Vienna, 2009.

[137] R. Long, W. Yang, and G. Huang, "Preparation and separation of epothilones with anticancer activity," Chemical Biology \& Drug Design, vol. 96, no. 2, pp. 785-789, 2020.

[138] S. Forli, "Epothilones: from discovery to clinical trials," Current Topics in Medicinal Chemistry, vol. 14, no. 20, pp. 2312-2321, 2014.

[139] L. T. Vahdat, "Clinical studies with epothilones for the treatment of metastatic breast cancer," Seminars in Oncology, vol. 35, 2 Suppl 2, pp. S22-S30, 2008.

[140] K. R. Brunden, B. Zhang, J. Carroll et al., "Epothilone D improves microtubule density, axonal integrity, and cognition in a transgenic mouse model of tauopathy," The Journal of neuroscience : the official journal of the Society for Neuroscience, vol. 30, no. 41, pp. 13861-13866, 2010.

[141] W. Xue, H. Zhang, Y. Fan et al., "Upregulation of Apol8 by epothilone D facilitates the neuronal relay of transplanted NSCs in spinal cord injury," Stem Cell Research \& Therapy, vol. 12, no. 1, pp. 1-12, 2021.

[142] D. Donovan and L. T. Vahdat, "Epothilones: clinical update and future directions," Oncology (Williston Park), vol. 22, no. 4, pp. 408-416, 2008.

[143] C. Kugler, C. Thielscher, B. A. Tambe et al., "Epothilones improve axonal growth and motor outcomes after stroke in the adult mammalian," Cell Reports.Medicine, vol. 1, no. 9, article 100159, 2020.

[144] E. L. Schwartz, "Antivascular actions of microtubule-binding drugs," Clinical cancer research : an official journal of the American Association for Cancer Research, vol. 15, no. 8, pp. 2594-2601, 2009.

[145] A. D. Tangutur, D. Kumar, K. V. Krishna, and S. Kantevari, "Microtubule targeting agents as cancer chemotherapeutics: an overview of molecular hybrids as stabilizing and destabilizing agents," Current Topics in Medicinal Chemistry, vol. 17, no. 22, pp. 2523-2537, 2017.

[146] M. Moudi, R. Go, C. Y. Yien, and M. Nazre, "Vinca alkaloids," International Journal of Preventive Medicine, vol. 4, no. 11, pp. 1231-1235, 2013.

[147] E. Martino, G. Casamassima, S. Castiglione et al., "Vinca alkaloids and analogues as anti-cancer agents: looking back, peering ahead," Bioorganic \& Medicinal Chemistry Letters, vol. 28, no. 17, pp. 2816-2826, 2018.

[148] R. Rahmani and X. J. Zhou, "Pharmacokinetics and metabolism of vinca alkaloids," Cancer Surveys, vol. 17, pp. 269-281, 1993.
[149] X. J. Zhou and R. Rahmani, "Preclinical and clinical pharmacology of vinca alkaloids," Drugs, vol. 44, no. 4, pp. 1-16, 1992.

[150] S. Lobert, "Neurotoxicity in cancer chemotherapy: vinca alkaloids," Critical Care Nurse, vol. 17, no. 4, pp. 71-79, 1997.

[151] C. Angelidis, Z. Kotsialou, C. Kossyvakis et al., "Colchicine pharmacokinetics and mechanism of action," Current Pharmaceutical Design, vol. 24, no. 6, pp. 659-663, 2018.

[152] T. Tateishi, P. Soucek, Y. Caraco, F. P. Guengerich, and A. J. Wood, "Colchicine biotransformation by human liver microsomes: identification of cyp3a4 as the major isoform responsible for colchicine demethylation," Biochemical Pharmacology, vol. 53, no. 1, pp. 111-116, 1997.

[153] R. Herran-Monge, A. Muriel-Bombin, M. Garcia-Garcia, A. Duenas-Laita, M. L. Fernandez-Rodriguez, and A. M. Prieto de Lamo, "Accidental fatal colchicine overdose," Medicina Intensiva, vol. 37, no. 6, pp. 434-436, 2013.

[154] E. Niel and J. M. Scherrmann, "Colchicine today," Joint Bone Spine, vol. 73, no. 6, pp. 672-678, 2006.

[155] Y. Finkelstein, S. E. Aks, J. R. Hutson et al., "Colchicine poisoning: the dark side of an ancient drug," Clinical Toxicology, vol. 48, no. 5, pp. 407-414, 2010.

[156] A. Urbaniak, F. Jousheghany, S. Pina-Oviedo et al., "Carbamate derivatives of colchicine show potent activity towards primary acute lymphoblastic leukemia and primary breast cancer cells-in vitro and ex vivo study," Journal of Biochemical and Molecular Toxicology, vol. 34, no. 6, article e22487, 2020.

[157] B. A. Winn, L. Devkota, B. Kuch et al., "Bioreductively activatable prodrug conjugates of combretastatin A-1 and combretastatin A-4 as anticancer agents targeted toward tumorassociated hypoxia," Journal of Natural Products, vol. 83, no. 4, pp. 937-954, 2020.

[158] L. Huang, J. Huang, H. Nie, Y. Li, L. Song, and F. Wu, "Design, synthesis and biological evaluation of combretastatin A-4 sulfamate derivatives as potential anti-cancer agents," RSC Medicinal Chemistry, vol. 12, no. 8, pp. 13741380, 2021.

[159] L. K. Folkes, M. Christlieb, E. Madej, M. R. Stratford, and P. Wardman, "Oxidative metabolism of combretastatin A-1 produces quinone intermediates with the potential to bind to nucleophiles and to enhance oxidative stress via free radicals," Chemical Research in Toxicology, vol. 20, no. 12, pp. 1885-1894, 2007.

[160] M. Weigel, L. Wang, and M. M. Fu, "Microtubule organization and dynamics in oligodendrocytes, astrocytes, and microglia," Developmental Neurobiology, vol. 81, no. 3, pp. 310-320, 2021.

[161] A. Roll-Mecak, "The tubulin code in microtubule dynamics and information encoding," Developmental Cell, vol. 54, no. 1, pp. 7-20, 2020.

[162] C. M. Waterman-Storer, A. Desai, J. C. Bulinski, and E. D. Salmon, "Fluorescent speckle microscopy, a method to visualize the dynamics of protein assemblies in living cells," Current Biology, vol. 8, no. 22, pp. 1227-1230, 1998.

[163] J. M. Cleary and W. O. Hancock, "Molecular mechanisms underlying microtubule growth dynamics," Current Biology, vol. 31, no. 10, pp. R560-R573, 2021.

[164] C. Janke and G. Montagnac, "Causes and consequences of microtubule acetylation," Current Biology, vol. 27, no. 23, pp. R1287-R1292, 2017. 
[165] H. Li and W. Wu, "Microtubule stabilization promoted axonal regeneration and functional recovery after spinal root avulsion," European Journal of Neuroscience, vol. 46, no. 1, pp. 1650-1662, 2017.

[166] J. Logie, A. N. Ganesh, A. M. Aman, R. S. Al-Awar, and M. S. Shoichet, "Preclinical evaluation of taxane-binding peptidemodified polymeric micelles loaded with docetaxel in an orthotopic breast cancer mouse model," Biomaterials, vol. 123, pp. 39-47, 2017. 